\title{
FUSÃO COMO ESTRATÉGIA DE CRESCIMENTO DE REDES DE COOPERAÇÃO EMPRESARIAL: UM ESTUDO DE CASO EM UMA REDE DE FARMÁCIAS
}

\section{RESUMO}

Este artigo teve como objetivo analisar as motivações, o processo e os resultados de uma estratégia de fusão estabelecida por três redes de cooperação empresarial. A pesquisa consistiu em um estudo de caso único, de caráter exploratório, com uma rede de farmácias, formada a partir da fusão de três redes, no estado do Rio Grande do Sul. A coleta de dados ocorreu por meio de seis entrevistas em profundidade, realizadas com atores diretamente envolvidos no processo. A principal motivação para a adoção desta estratégia foi o aumento da competitividade no setor e a necessidade de ampliar ganhos de escala na negociação com fornecedores. Os resultados mostram que as redes envolvidas não tinham a dimensão exata dos benefícios que poderiam ser alcançados, sendo estes superiores à motivação inicial de obter maior poder de mercado. Também se verificou que não houve uma estratégia definida para a formação da nova rede, sendo a fusão consolidada por ações de aproximação entre as redes. A pesquisa contribuiu para o avanço do entendimento do processo que envolve a fusão entre redes. Do ponto de vista teórico, o estudo descreve as etapas do processo de fusão; a contribuição gerencial consiste na apresentação de subsídios para a implementação de novas fusões.

Palavras-chave: Redes Empresariais; Redes de Pequenas Empresas; Fusões; Relações Interorganizacionais.

\section{MERGER AS A GROWTH STRATEGY OF BUSINESS NETWORKS: A CASE STUDY OF A DRUGSTORE NETWORK}

\begin{abstract}
This article aims to analyze the motivations, the process and the results of a merger strategy established by three business networks. The research consisted in an exploratory single case study. It was analyzed a business network composed by drugstores, formed from the merger of three business networks in the state of Rio Grande do Sul. Data collection occurred through six in-depth interviews conducted with actors directly involved. The main motivation for the adoption of this strategy was the increased competition in the sector and the need to expand economies of scale in negotiating with suppliers. The results also reveal that the networks involved did not have the exact notion of the benefits that could be achieved, which are higher than the initial motivation to get increased market power. It was also found that there was no defined strategy for the formation of the new business network. The merger was consolidated by actions of approach among the networks. The research contributes to the understanding of mergers among networks. From a theoretical point of view, the study describes the merger process; the managerial contribution consists in the presentation of steps for the implementation of new mergers.
\end{abstract}

Keywords: Business Networks; Small-Firm Networks; Mergers; Inter-Organizational Relationships. 


\section{FUSIÓN AS RED DE COOPERACIÓN ESTRATEGIA DE CRECIMIENTO DE NEGOCIO: UN ESTUDIO} DE CASO EN UNA RED DE FARMACIAS

\section{RESUMEN}

Este artículo tiene como objetivo analizar las motivaciones, el proceso y los resultados de una estrategia de fusión establecido tres redes de cooperación empresarial. La investigación consistió en un estudio de caso único, de carácter exploratorio, con una red de farmacias, formado a partir de la fusión de tres redes en el estado de Rio Grande do Sul. Los datos fueron recolectados a través de seis entrevistas en profundidad, realizado con participado directamente en los actores del proceso. La principal motivación para la adopción de esta estrategia era aumentar la competitividad en el sector y la necesidad de ampliar las economías de escala en la negociación con los proveedores. Los resultados muestran que las redes implicadas no tenían la dimensión exacta de los beneficios que se podrían alcanzar, que son más altos que la motivación inicial para conseguir mayor poder de mercado. También se encontró que no había ninguna estrategia definida para la formación de la nueva red, y el enfoque de fusión codificada por acciones entre redes. La investigación ayudó a avanzar en la comprensión del proceso que implica la fusión de las redes. Desde un punto de vista teórico, el estudio describe los pasos de la fusión; contribución ejecutivo, consiste en el tratamiento de las subvenciones para la implantación de nuevas fusiones.

Palabras clave: Redes Empresariales; Redes de la Pequeña Empresa; Fusiones; Relaciones entre Organizaciones.

\footnotetext{
${ }^{1}$ Universidade de Santa Cruz do Sul - UNISC. Brasil. E-mail: wb.soares@ hotmail.com

${ }^{2}$ Doutor em Administração pela Universidade Federal do Rio Grande do Sul - UFRGS. Professor da Universidade do Vale do Rio dos Sinos - UNISINOS. Brasil. E-mail: douglaswegner@ hotmail.com

${ }^{3}$ Doutor em Administração pela Universidade Federal do Rio Grande do Sul - UFRGS. Professor do Programa de PósGraduação em Administração da Universidade de Santa Cruz do Sul - Unisc. Brasil. E-mail: pcdolci@unisc.br
} 


\section{INTRODUÇÃO}

Como resposta às pressões de um ambiente altamente competitivo, muitas organizações optam pelo estabelecimento de relações interorganizacionais cooperativas de diversos formatos e características (ver, por exemplo, Olave \& Amato, 2001; Todeva, 2006). Pequenas empresas têm optado pela criação de redes de cooperação empresarial para reduzir suas dificuldades competitivas. Tal é a importância que redes e relações interorganizacionais representam para as empresas, que em determinados setores a competição não está mais confinada ao nível das firmas, mas caracteriza-se como um fenômeno no nível das redes (Gomes-Casseres, 1994; Lazzarini, 2007). As redes incapazes de ampliar o número de participantes e desenvolver novos recursos correm o risco de não serem capazes de reter e atrair membros. O número de membros gera efeitos de escala, favorecendo a negociação com fornecedores e clientes, bem como o estabelecimento de barreiras à competição.

Os benefícios proporcionados pela cooperação às pequenas empresas estão refletidos no grande número de redes criadas no Brasil nos últimos anos: de acordo com o Serviço Brasileiro de Apoio às Micro e Pequenas Empresas (Sebrae, 2012) foram criadas mais de 800 redes no país em uma década. Embora a consolidação no mercado seja um objetivo de todas as redes, a realidade tem se mostrado menos favorável. $\mathrm{O}$ estudo de Wegner, Alievi e Begnis (2015) verificou que, de um conjunto de 28 redes constituídas entre os anos 2000 e 2012 no centro-leste do Estado do Rio Grande do Sul, a maioria está em processo de declínio, ou então já encerrou suas atividades. Tais resultados confirmam os achados de outros estudos, que revelam a alta taxa de insucesso das redes interorganizacionais (Toigo \& Alba, 2010; Wegner \& Padula, 2011; Sebrae, 2012). Outra pesquisa com pousadas do interior de Minas Gerais identificou que "apesar da existência da cooperação, a sua baixa intensidade aponta para um baixo aproveitamento do seu potencial de crescimento" (Oliveira \& Gonçalves, 2011, p.53).

Uma possível estratégia de consolidação é a promoção da intercooperação ou a fusão de redes, visando a obtenção de sinergias. Em países como a Alemanha essa estratégia já é utilizada há muito tempo pelas redes empresariais, com diversos exemplos de sucesso (Wegner \& Padula, 2010; Wegner \& Padula, 2011). Com a fusão ocorrem sinergias entre as redes, permitindo melhores negociações com fornecedores, ampliação do portfolio de serviços ofertados aos participantes e melhores condições de sustentar uma estrutura de gestão com profissionais contratados. A rede acelera o processo de consolidação e mantém a motivação e interesse dos associados na cooperação. Redes com pequeno número de participantes têm a possibilidade de unir esforços e desenvolver recursos estratégicos para a cooperação.
Ainda que a estratégia de intercooperação e fusão de redes cooperativas seja mencionada pela literatura, não foram encontrados estudos que analisam detalhadamente como ela ocorre. Nesse sentido, o presente estudo parte da seguinte pergunta de pesquisa: Como ocorre a fusão de redes de cooperação? Para responder essa pergunta, definiu-se os seguintes objetivos: compreender o que leva redes de cooperação já estabelecidas a adotarem a estratégia de fusão; identificar os resultados obtidos e descrever como esse processo é desenvolvido. A pesquisa foi realizada por meio de um estudo de caso único, que consiste na fusão de três redes de cooperação no estado do Rio Grande do Sul, formando uma única rede. Por meio de entrevistas com os principais atores envolvidos, identificou-se um conjunto de fatores que explicam os motivos e resultados da estratégia. A pesquisa também descreve o processo de fusão das redes, gerando contribuições teóricas e gerenciais para o campo organizacional.

O artigo é estruturado da seguinte forma: parte-se de uma revisão de literatura sobre relações interorganizacionais e estratégias de crescimento (seção 2), seguido da descrição do método de pesquisa adotado (seção 3), apresentação do caso (seção 4), implicações da pesquisa (seção 5) e considerações finais (seção 6).

\section{RELAÇÕES INTERORGANIZACIONAIS}

O crescimento na adoção de estratégias interorganizacionais se torna evidente pela variação de formatos de relações de cooperação e os diferentes contextos em que elas são utilizadas Este estudo aborda um modelo específico de relações interorganizacionais horizontais, denominado de redes de cooperação empresarial. Mesmo que utilizando nomenclaturas distintas, como redes associativas (Mañas \& Pacanhan, 2004), centrais de negócios (Xavier Filho, Chagas, Santos, Romero \& Carneiro, 2010; Tálamo \& Carvalho, 2010), e redes de cooperação empresarial (Verschoore \& Balestrin, 2008), tais estudos definem as redes empresariais como um conjunto de empresas similares, que articulam suas atividades para alcançar objetivos coletivos. Para que elas alcancem resultados, é preciso que haja ao menos um objetivo comum (Balestrin \& Verschoore, 2008). As redes são formadas incialmente com o objetivo de reduzir incertezas e riscos, organizando atividades a partir da coordenação e cooperação entre empresas (Leon, 1998). A cooperação passa a existir não apenas pelo prosaico desejo de pertencer, mas pela vontade - ou necessidade - de obter algo por meio deste pertencer (Olson, 1999).

Um dos conceitos básicos para a consolidação das redes é que quanto maior o número de empresas envolvidas, maior a possibilidade da rede obter ganhos competitivos (Balestrin \& Verschoore, 2008). Assim, estas redes podem gerar benefícios exclusivos, que 
somente as empresas integrantes podem usufruir, tornando-as mais fortes na comparação com aquelas que não integram o grupo constituído. Logo, os resultados estão diretamente relacionados a um "conjunto de interações sistemáticas de aprendizagem entre diversos atores presentes em seu contexto de inserção" (Zancan, Santos, Costa \& Cruz, 2013, p. 664). Isto quer dizer que, quanto maior o número de participantes, maior o potencial de ganho. Todavia, também será maior a complexidade da gestão desta rede. A operação de uma rede empresarial já tende a ser mais complexa do que a gestão de uma empresa individual, e a ampliação do número de firmas envolvidas aumenta ainda mais os desafios de coordenação e governança (Provan e Kenis, 2007). Portanto, ao mesmo tempo em que uma rede adota estratégias de crescimento, deve considerar os riscos e dificuldades inerentes a esse processo.

Autores como Hitt, Ireland e Hoskisson (2002), Mintzberg, Lampel, Quinn e Ghoshal (2006) e Barney e Hesterly (2008) apresentam estratégias de crescimento organizacional. Estas estratégias ajudam a levar a empresa até o seu objetivo de forma segura e planejada. No caso das redes, ainda são poucos os estudos que investigam suas estratégias de crescimento. O estudo de Gro $\beta$ (2003) serviu de referência para outras pesquisas desenvolvidas acerca do tema (Wegner \& Padula, 2011).

Diversas estratégias podem ser adotadas por redes empresariais para gerar crescimento, conforme a tipologia proposta por Gro $\beta$ (2003) e utilizada por Wegner e Padula (2011). Duas são denominadas estratégias básicas, que objetivam o crescimento da rede a partir de seus negócios atuais: penetração de mercado e aumento de eficiência. A primeira refere-se a captar novos associados para ampliar a rede e a segunda busca otimizar os resultados com os associados atuais, procurando aumentar a fidelidade deles com a rede. Fröhlich (2003) descreve o caso da rede alemã Intersport, que desenvolveu marcas próprias e ações para aumentar a integração dos associados ao padrão da rede. Embora as duas estratégias básicas para aumento da eficiência possam gerar resultados de curto prazo, Gro $\beta$ (2003) acredita que eles não são uma solução de longo prazo para as necessidades estratégicas das redes. Como complemento, o autor apresenta estratégias com foco externo à rede: diversificação, horizontalização, verticalização e internacionalização.

A diversificação consiste em acrescentar à rede associados em segmentos de negócio correlatos ao original e que permitam gerar sinergias (Gro $\beta, 2003$; Wegner \& Padula, 2010) ou então realizar parcerias com empresas de setores complementares para ofertar novos produtos (Wegner \& Padula, 2011). A estratégia de verticalização consiste em realizar parcerias ou integrar outros elos da cadeia de valor e com isso melhorar a posição competitiva da rede (Gro $\beta, 2003)$. Redes podem, por exemplo, optar por estabelecer empresas que sejam fornecedoras de produtos específicos aos seus associados, substituindo fornecedores parceiros. $\mathrm{Na}$ outra direção da cadeia de valor, podem optar pelo estabelecimento de filiais próprias ou sistemas de franquias, realizando a função exercida por seus próprios associados (Wegner \& Padula, 2011). Em contrapartida, a estratégia de horizontalização, executada por meio de parceiras, cooperações e fusões com outras redes já existentes, de acordo com Wegner \& Padula (2010), pode gerar o crescimento com menores riscos, porque internaliza a experiência dos novos parceiros nos respectivos mercados. Essa foi, por exemplo, a estratégia adotada na fusão entre a Nord-West e a Ring-Schuh (ambas do varejo de calçados) na década de 1970 na Alemanha, criando a rede ANWR e gerando crescimento com pequeno risco devido à semelhança dos negócios (Wellenbeck, 2001).

Por fim, outra estratégia de crescimento é a internacionalização, quando a rede já atingiu uma expansão significativa no mercado interno (Wegner \& Padula, 2010). Essa estratégia pode ser implementada através da conquista de associados em outros países, formação de alianças internacionais (Wegner \& Padula, 2011), abertura de filiais da rede no exterior ou através de uma organização supranacional (Gro $\beta, 2003)$. A opção pela internacionalização pode ser feita por redes que já atingiram um alto nível de consolidação em seu país de origem, sendo, portanto, de difícil execução para a maioria das redes brasileiras, que em sua maioria atuam regionalmente e ainda se encontram em processo de desenvolvimento. Dentre as estratégias propostas por Gro $\beta$ (2003), este artigo analisará a estratégia de fusão entre redes, abordada na próxima seção.

\section{Motivos, processo e resultados da fusão entre redes}

A formação de redes de cooperação é explicada por diversas abordagens teóricas, como a Teoria da Dependência de Recursos (TDR), a Visão Relacional (VR) e a Teoria dos Custos de Transação (TCT). De maneira similar, estas teorias podem ser utilizadas como base para compreender os motivos que levam redes de cooperação a buscar a fusão. Na perspectiva da TDR, as organizações dependem de recursos externos e adotam estratégias colaborativas com outros atores para reduzir a dependência em relação aos recursos que eles detêm (Pfeffer \& Salancik, 2003). Segundo a Visão Relacional, a principal motivação para a cooperação é a combinação de recursos estratégicos e a geração de ganhos relacionais, que só podem ser obtidos a partir da relação entre organizações (Dyer \& Singh, 1998). Por sua vez, na Teoria dos Custos de Transação a decisão de cooperar deriva da possibilidade de reduzir custos de transação e somente ocorrerá quando essa forma de governança das transações for mais adequada que mecanismos de mercado ou hierarquia (Williamson, 2005; Arbage \& Balestrin, 2007).

Assim como a cooperação interorganizacional, as fusões constituem uma maneira rápida de crescer e 
entrar em novos mercados (Camargos \& Barbosa, 2003). Além disso, esta estratégia de crescimento proporciona aos envolvidos importantes vantagens competitivas de diferenciação ou liderança de custos (Porter, 1996). Portanto, o ato de fundir-se a outras redes é considerado uma decisão estratégica que pode ser explicada pelas mesmas vantagens obtidas através da formação de redes e alianças.

Algumas etapas são consideradas essenciais para que uma fusão se consolide. Latorre (2013, p. 55) destaca que "a pesquisa, a seleção e a negociação com empresas candidatas constitui um dos pilares fundamentais" para o sucesso de uma fusão. Além disso, esta decisão envolve a elaboração do perfil e o contato com potenciais candidatos. Burger (2013) também relaciona itens de avaliação indispensável na hora da formação de uma fusão. Embora direcionados para empresas individuais, todos se aplicam à cooperação entre redes, como por exemplo, saber se os números da empresa são fidedignos de sua realidade. Além disso, é importante averiguar se o negócio é rentável e a empresa ganha dinheiro e tem crescido; se a empresa é voltada para o mercado; o porquê de sua escolha em detrimento de outra; qual sua liquidez; haveria interessados em adquiri-la?; e por fim, a qualidade da equipe da empresa. Pensando tal análise do ponto de vista da cooperação entre redes, pode-se substituir a qualidade da equipe pela qualidade das empresas participantes das redes envolvidas na cooperação. Estes itens, aliados aos processos identificados por Latorre (2013), aumentam a confiabilidade em um processo de fusão.

Além dos planos de integração física e financeira, outro aspecto que deve ser considerado no momento da transição de estratégias é o plano de recursos humanos. Latorre (2013) destaca que na estrutura organizacional, as relações de subordinação, plano de pessoal, missão, visão, valores e pacotes de benefícios são componentes-chave para a consolidação inicial de uma fusão.

Como resultados da cooperação, e que também são esperados na fusão entre redes de cooperação, pode-se destacar a obtenção de maior escala e poder de mercado, geração de soluções coletivas, redução de custos e riscos, acúmulo de capital social e maximização dos lucros (Balestrin \& Verschoore, 2008; Camargos \& Barbosa, 2003). Outros resultados da cooperação interorganizacional que podem ser estendidos à fusão entre redes são a aquisição de recursos necessários à competição (Brass, Galaskiewicz, Greve \& Tsai, 2004), a redução da incerteza associada à dinâmica concorrencial, a busca de legitimidade no contexto em que as organizações estão inseridas (Oliver, 1990) e a aprendizagem interorganizacional (Ahuja, 2000).

Considerando a revisão teórica sobre as motivações para o processo de fusão de redes empresariais, o processo de fusão e os resultados esperados, apresenta-se na Figura 1 o modelo de pesquisa adotado no estudo.

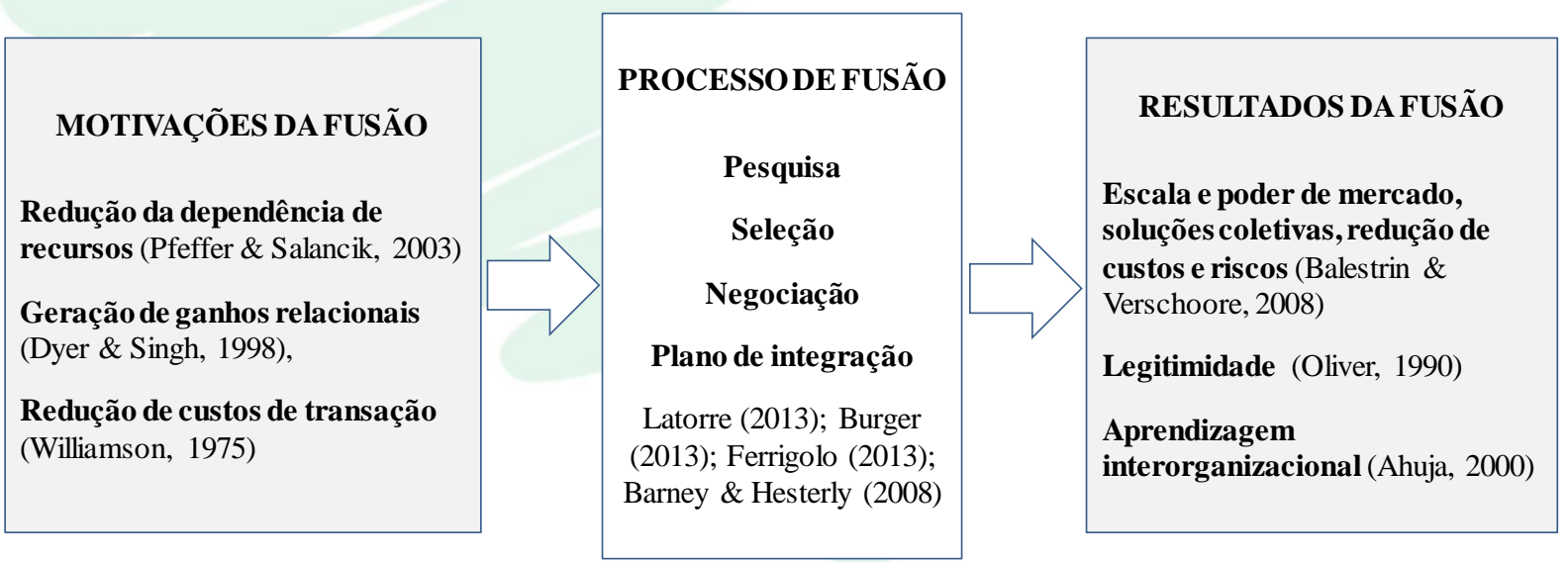

Figura 1 - Modelo de pesquisa

Fonte: Desenvolvido pelos autores

A seção seguinte apresenta os procedimentos metodológicos adotados e é seguido da apresentação dos resultados.

\section{PROCEDIMENTOS METODOLÓGICOS}

Esta pesquisa é qualitativa e de caráter exploratório com um caso único para analisar o processo de fusão de redes empresariais. O método utilizado é o de estudo de caso, pois busca responder perguntas do tipo como e por que para fenômenos contemporâneos inseridos na vida real (Yin, 2005). O estudo de caso torna-se um método de relevância porque focaliza acontecimentos contemporâneos e não exige controle sobre eventos comportamentais (Yin, 2005). Este tipo de pesquisa se caracteriza por aprofundar a análise sobre o objeto de estudo (Mascarenhas, 2012). O estudo qualitativo é adequado, pois busca descrever a complexidade de uma situação e analisar mais profundamente a interação das variáveis (Richardson, 1999). Estudos exploratórios, como este, 
têm a intenção de criar mais familiaridade com o tema da pesquisa. Assim, a pesquisa envolve a análise do caso, a partir dos elementos encontrados na revisão da literatura sobre motivações, processo de fusão e os seus resultados.

Com o intuito de compreender o processo de fusão, e todos os elementos que o cercam, fez-se necessário escolher uma rede que tivesse passado por tais processos. Esta pesquisa abordou o processo que envolveu a fusão que originou a rede Vida Farmácias. A rede de empresas selecionada é resultado da fusão de outras três redes. Em julho de 2013 as redes Farmavale, Vida Farmácias e Vida \& Saúde resolveram integrar suas operações, visando aumentar o alcance e aprofundar as negociações de suas afiliadas. A rede tem hoje 240 lojas espalhadas em mais de 100 municípios gaúchos.

Foram realizadas seis entrevistas, com todos os principais atores envolvidos na fusão. Para manter o anonimato dos entrevistados, optou-se pelo uso de uma nomenclatura específica, conforme apresentado na Tabela 1. Os dados foram coletados pessoalmente, com cada um dos seis entrevistados, respeitando um roteiro de 17 perguntas, pré-estabelecidas, assim divididas: quatro questões sobre as motivações da fusão; oito questões sobre o processo, três perguntas sobre os resultados da fusão e duas perguntas abertas, de caráter geral.

Tabela 1 - Descrição dos entrevistados

\begin{tabular}{|c|l|l|}
\hline ENTREVISTADO & \multicolumn{1}{|c|}{ CARGO ANTERIOR } & \multicolumn{1}{|c|}{ CARGO ATUAL } \\
\hline E1 & $\begin{array}{l}\text { Ex-presidente da rede Vida Farmácias, } \\
\text { participante do processo de fusão }\end{array}$ & $\begin{array}{l}\text { Presidente de Rede Vida Farmácias, } \\
\text { resultante da fusão }\end{array}$ \\
\hline E2 & $\begin{array}{l}\text { Ex-presidente da rede Farmavale, } \\
\text { participante do processo de fusão }\end{array}$ & $\begin{array}{l}\text { Vice-presidente da Vida Farmácias, } \\
\text { resultante da fusão }\end{array}$ \\
\hline E3 & $\begin{array}{l}\text { Ex-presidente da rede Vida \& Saúde, } \\
\text { participante da fusão }\end{array}$ & $\begin{array}{l}\text { Diretor Financeiro da Vida Farmácias, } \\
\text { resultante da fusão }\end{array}$ \\
\hline E4 & $\begin{array}{l}\text { Fundador da rede Farmavale } \\
\text { (participante do processo de fusão) e } \\
\text { incentivador da fusão }\end{array}$ & $\begin{array}{l}\text { Diretor da Vida Farmácias, resulta da } \\
\text { fusão }\end{array}$ \\
\hline E5 & Empresário associado à Vida Farmácias e anteriormente vinculado à rede Farmavale \\
\hline E6 & Empresário associado à Vida Farmácias e anteriormente vinculado à rede Farmavale \\
\hline
\end{tabular}

Fonte: Desenvolvido pelos autores

A partir do levantamento teórico realizado, elaborou-se o protocolo de estudo de caso, que se destina a orientar o pesquisador ao realizar a coleta de dados de um estudo de caso (Yin, 2005). Esse protocolo, aponta Yin (2005), como relevante para chegar à confiabilidade, pois fornece informações para que a pesquisa quando repetida sob as mesmas condições obtenha os mesmos resultados. Assim, com os objetivos definidos, os entrevistados escolhidos e as perguntas elaboradas, um pré-teste foi aplicado com o entrevistado aqui denominado E4, validando o instrumento. Esta escolha considerou a participação do entrevistado no processo, e sua importância para que a fusão se consolidasse.

Marconi e Lakatos (2003) destacam a importância deste teste piloto para verificar sua fidedignidade e analisar se todos os dados recolhidos são necessários à pesquisa, ou ainda, se nenhuma informação relevante não tenha sido contemplada. Gil (1999, p. 132) também ressalta a importância de testar cada instrumento antes da finalização do modelo de coleta para "aperfeiçoar os procedimentos de aplicação, testar o vocabulário empregado nas questões e assegurar-se de que as questões ou observações a serem feitas possibilitem medir as variáveis que se pretende medir".

Para compreender o processo de intercooperação de redes proposto no presente estudo, a principal técnica de coleta de dados foi a entrevista. Como segunda fonte de dados foram utilizados informações disponibilizadas nos sites das redes envolvidas e foram solicitados documentos relacionados ao processo analisado, como atas de assembleias e de reuniões realizadas pelas redes. Devido a questões de sigilo, esses documentos não puderam ser disponibilizados nem utilizados como fonte de evidências.

Yin (2005) destaca que em pesquisas qualitativas, várias entrevistas devem ser realizadas, preferencialmente conduzidas no ambiente natural. Todas as seis entrevistas foram gravadas e a primeira etapa da organização do material aconteceu com a transcrição das conversas. Todas as entrevistas foram repassadas para arquivos de texto e organizadas de acordo com o assunto abordado. Uma das ferramentas utilizadas para a análise dos dados foi a comparação, a qual Godoi, Mello e Silva (2006) destacam como 
importante balizador para categorizar e estabelecer fronteiras acerca do assunto abordado.

Já a análise de conteúdo foi utilizada porque possibilita ao pesquisador qualificar o material analisado cuja presença ou frequência de aparição pode significar alguma coisa para o objetivo analítico escolhido, como explica Bardin (1977), classificandoos em várias unidades de códigos que são préconstruídas pelo pesquisador. Foram determinadas categorias a partir dos núcleos de sentido encontrados, sendo separados em categorias finais (motivações para a fusão, o processo de fusão e os resultados da fusão), intermediárias (atividades em cada um das três categorias) e iniciais (elementos de cada uma das categorias encontradas a partir das entrevistas). Os principais objetivos das análises foram: (i) identificar as principais motivações que as empresas tiveram para fazer parte da nova rede; (ii) conhecer o processo em si da fusão entre as empresas; e (iii) determinar os principais resultados a partir do processo de fusão. São apresentados alguns exemplos das categorias encontradas no estudo de caso e a síntese dessas categorias.

\section{ANÁLISE DOS RESULTADOS}

Nesta seção são descritos os resultados obtidos por meio da pesquisa qualitativa que buscou compreender o processo de fusão pelo qual passaram as redes Vida, Farmavale e Vida \& Saúde. Para tanto foram realizadas entrevistas com atores chave envolvidos no processo. A primeira subseção apresenta as motivações das redes para realização da fusão, a segunda descreve o processo de fusão e a terceira os resultados alcançados pelas redes.

\section{Motivações}

Todos os entrevistados concordam que a necessidade de maior poder de mercado foi determinante para que o processo de fusão fosse discutido e implantado pelas três redes. O presidente da rede resultante da fusão afirma que o volume de compras foi a principal motivação para que as redes se aproximassem, citando como exemplo as negociações que aconteciam antes da fusão: "Antes eu comprava R\$20 mil por mês da distribuidora. A Farmavale comprava outros R \$20 mil e a Vida \& Saúde, nem isso. Agora, a nova Rede compra mais de $\mathrm{R} \$ 300$ mil por mês deles. Ou seja, quando o fornecedor escuta que a negociação é para 240 lojas, em 144 municípios, isso faz a diferença".

$\mathrm{O}$ entrevistado 2, da antiga rede Farmavale e atual vice-presidente da Vida Farmácias, confirma como principal motivo "uma maior representatividade junto aos fornecedores". O entrevistado salienta que esse aumento de volume era imprescindível para ganhar escala e conseguir negociar direto com a indústria, sem a intermediação de distribuidores. Essa impressão também é compartilhada pelo presidente da extinta rede Vida \& Saúde, que recorda as tentativas frustradas de negociações para suas associadas. O baixo volume de compra não permitia negociações satisfatórias junto aos fornecedores.

O entrevistado 4, um dos principais apoiadores da fusão entre as redes, revela que com a forte concorrência, principalmente pela chegada de outras grandes redes na região, esta estratégia de crescimento era imprescindível para a sobrevivência.

Embora a necessidade de maior escala e poder de mercado tenham motivado a aproximação entre as redes, após esta primeira etapa os participantes identificaram novos benefícios que poderiam ser obtidos. Os entrevistados apontaram ainda como motivações a geração de soluções coletivas, a redução de custos e riscos e a busca pela maximização dos lucros. A geração de soluções coletivas ficou evidenciada já no início do processo, por meio da confecção de um encarte de ofertas robusto e atrativo, com 12 páginas. Também se pode destacar como soluções coletivas a utilização da publicidade compartilhada, através de veiculação de propagandas e os cursos de aperfeiçoamento oferecidos aos associados.

O entrevistado 2 destaca que a Rede tem "um programa de treinamento que propicia às farmácias com dois ou três funcionários, manter sua equipe treinada, com atendimento padronizado". O empresário E5, um dos associados da Vida Farmácias destaca a importância dos treinamentos oferecidos pela Rede: "além de serem oferecidos com frequência, os treinamentos padronizam o atendimento e são gratuitos".

Outra categoria destacada pelos entrevistados, que motivou a fusão foi a redução de custos e riscos. $\mathrm{O}$ presidente sintetiza esta motivação como a "necessidade de comprar melhor e mais barato", o que, de certa forma, se entrelaça com a quarta e última categoria, que é a maximização dos lucros. Portanto, as motivações que levaram as três redes a iniciar o processo de fusão estão sintetizadas na Tabela 2. 
Tabela 2 - Categoria final motivações

\begin{tabular}{|c|c|}
\hline CATEGORIAS INICIAIS & $\begin{array}{c}\text { CATEGORIAS } \\
\text { INTERMEDIÁRIAS }\end{array}$ \\
\hline $\begin{array}{l}\text { - Busca por um maior volume de compras } \\
\text { - Possibilidade de negociar direto com a indústria } \\
\text { - A forte concorrência, imposta pela chegada de grandes redes }\end{array}$ & $\begin{array}{l}\text { Necessidade de maior poder de } \\
\text { mercado }\end{array}$ \\
\hline $\begin{array}{l}\text { - Melhoria no encarte, que tinha apenas quatro páginas } \\
\text { - Maior participação na mídia - publicidade } \\
\text { - Qualificação dos recursos humanos - cursos e treinamentos }\end{array}$ & Geração de soluções coletivas \\
\hline $\begin{array}{l}\text { - A certeza da negociação com o fornecedor ser otimizada } \\
\text { - Redução de despesas, com participação cooperativa nas ações }\end{array}$ & Redução de custos e riscos \\
\hline - Crescimento em escala - ampliação do número de lojas & Maximização dos lucros \\
\hline
\end{tabular}

Fonte: Desenvolvido pelos autores

\section{Processo de fusão}

A análise do caso permite compreender que o processo de fusão das três redes ocorreu em quatro etapas, que consistiram em definição da estratégia, seleção dos parceiros, negociação e implementação. Quanto às estratégias, os entrevistados foram unânimes ao afirmar que não houve nenhuma estratégia formal definida, apenas a certeza de que o objetivo central era aumentar o número de lojas associadas. Assim, nenhum plano específico foi elaborado pelos envolvidos na liderança do processo de fusão. Esta primeira etapa representa apenas a decisão estratégica de realizar a fusão.

A escolha dos parceiros também foi feita sem uma classificação criteriosa. Na verdade, não houve uma seleção efetiva, e sim a sequência de um processo que se iniciou sem muita pretensão, em meados de 2012, e foi tomando forma com a manifestação de interesse por parte de representantes de algumas redes de farmácias que se conheciam. Todos os diretores que hoje gerenciam a Vida Farmácias lembram que a afinidade e o conhecimento que eles mantinham entre si foi determinante para que Vida, Farmavale e Total Farma - que desistiu da fusão - levassem o projeto adiante. Enquanto estas três acertavam os detalhes da fusão, a participação da Vida \& Saúde aconteceu em um segundo momento. Indicada por fornecedores, esta rede participou de reuniões com os demais diretores, e passou a integrar o processo de fusão da Vida, que praticamente até a sua efetivação contava com a participação das quatro redes.

Embora a fusão tenha se consolidado apenas com a Vida, Farmavale e Vida \& Saúde, a Total Farma participou de toda a negociação, desde agosto de 2012, até praticamente a sua consolidação, em julho de 2013.
A primeira medida após a decisão de cooperar e avançar com o processo de fusão foi explanar seus resultados aos parceiros, tais como volume de vendas, margens e lucratividade, por exemplo, para os futuros parceiros. Depois disso a negociação seguiu sem um roteiro definido. Os diretores envolvidos no processo de fusão concordam que "as coisas foram acontecendo naturalmente". Enquanto o atual presidente lembra que este processo foi muito tranquilo, pois das quatro redes que participavam, representantes de três delas já se conheciam, o entrevistado E2 salienta que alguns problemas surgiram devido à diferença de estruturas das redes, mas que logo foram superados.

Processo iniciado, seleção concluída e negociação efetuada, os diretores passaram para a implementação da nova rede. Todos os entrevistados afirmam que a formalização da nova rede era apenas o processo de colocar no papel o que já vinha sendo executado na prática, há pelo menos um ano. Ainda assim, com esta formalização, algumas medidas foram tomadas de imediato. A diretoria da nova Vida Farmácias foi escolhida por aclamação, não houve votação. Depois definiu-se quais seriam as obrigações de cada diretor e o novo estatuto foi encaminhado.

A implementação da Vida seguiu com definições sobre a finalidade das sedes regionais, que foram mantidas, devido a aproximação com o cliente, roupagem da marca, novo nome da rede, operacionalização do processo, comunicação e divulgação da fusão e a migração de processos das antigas redes para a Vida Farmácias. Segundo os atuais diretores, a implementação da nova rede está totalmente concluída. A Tabela 3 apresenta os principais apontamentos dos entrevistados acerca do processo que envolveu a fusão, que originou a rede Vida Farmácias. 
Tabela 3 - Categoria final processo de fusão

\begin{tabular}{|l|c|}
\hline \multicolumn{1}{|c|}{ CATEGORIAS INICIAIS } & \multicolumn{1}{|c|}{ CATEGORIAS } \\
INTERMEDIÁRIAS
\end{tabular}

Fonte: Desenvolvido pelos autores

\section{Resultados}

Os resultados da fusão, indicados pelos entrevistados, refletem exatamente os motivos pelos quais a fusão foi estabelecida. O poder de mercado alcançado possibilitou que a Vida Farmácias passasse a negociar diretamente com a indústria. Isso representou descontos de até $25 \%$ nas negociações e o enfrentamento em iguais condições com as grandes redes do mercado. O E3 lembra que "nos tempos da Vida \& Saúde muito correu atrás da indústria, sempre sem sucesso. Agora o cenário é totalmente diferente. Agora são eles que vêm nos procurar". Para exemplificar a importância do aumento da competitividade com o ganho em escala, o entrevistado relembra uma história que o intrigava quando era presidente da Vida \& Saúde: "Eu lembro que via a concorrência vender o nebulizador a $\mathrm{R} \$ 99,00$ e não conseguia entender como aquilo era possível, pois eu pagava $\mathrm{R} \$ 98,00$ na mesma mercadoria. Agora, comprando pela Rede, eu entendo: o mesmo nebulizador me custa R $\$ 64,00 "$.

O segundo grupo de benefícios identificados pelos entrevistados foi a geração de soluções $e$ aprendizagem coletiva. Nesta categoria enquadram-se o aperfeiçoamento do encarte, a disponibilização de cursos e treinamentos para os funcionários e a utilização de benefícios oferecidos pela Federação
Brasileira das Redes Associativas de Farmácias (Febrafar).

Outro grande benefício destacado por todos os entrevistados foi a implantação do cartão fidelidade na Rede. Destacada como uma ferramenta de inovação colaborativa, o cartão vai além da alavancagem de vendas e transações financeiras. Ele permite aos gestores monitorar e mapear uma série de informações, que ajudam no gerenciamento do negócio. O sistema integrado, no qual o cartão fidelidade está incluso, disponibiliza informações exclusivas, divididas por segmento e por clientes que operam o cartão. $\mathrm{O}$ vicepresidente da Vida Farmácias ressalta que esse "foi um dos maiores ganhos que ocorreu a partir da fusão, haja vista que as lojas que estão operando nesse sistema aumentaram entre $40 \%$ e $50 \%$ suas vendas".

Finalizando a relação de benefícios alcançados por meio da fusão entre Vida, Farmavale e Vida \& Saúde, pode-se destacar o reconhecimento no mercado. Os entrevistados destacam que com o tamanho que eles alcançaram - trata-se da terceira maior rede do Rio Grande do Sul - tudo é facilitado. Hoje, o reconhecimento possibilita que a Rede consiga apoio de fornecedores para suas ações, como por exemplo, a feira anual que ela realiza para seus associados, ou até mesmo para a oferta de cursos e treinamentos oferecidos aos associados. A síntese desses resultados é apresentada na Tabela 4 . 
Tabela 4 - Categoria final resultados

\begin{tabular}{|c|c|}
\hline CATEGORIAS INICIAIS & $\begin{array}{c}\text { CATEGORIAS } \\
\text { INTERMEDIÁRIAS }\end{array}$ \\
\hline $\begin{array}{l}\text { - Possibilidade de competir em igualdade com as grandes do mercado } \\
\text { - Agora a negociação é feita diretamente com a indústria } \\
\text { - Os descontos aumentaram de } 5 \% \text { para } 25 \% \text { nas negociações }\end{array}$ & Poder de Mercado \\
\hline $\begin{array}{l}\text { - Ampliação do encarte promocional } \\
\text { - A Rede disponibiliza cursos e treinamentos para os funcionários } \\
\text { - } \quad \text { Com a fusão, pôde-se gozar dos benefícios oferecidos pela Febrafar }\end{array}$ & $\begin{array}{l}\text { Geração de soluções e } \\
\text { aprendizagem coletiva }\end{array}$ \\
\hline - O cartão fidelidade propicia grandes vantagens para os associados & Inovação colaborativa \\
\hline $\begin{array}{l}\text { - A possibilidade de veiculação de propagandas na grande mídia torna } \\
\text { a Rede conhecida } \\
\text { - Com o reconhecimento, conseguem-se facilmente patrocínios e } \\
\text { apoio para suas feiras e/ou programa de treinamentos }\end{array}$ & $\begin{array}{l}\text { Reconhecimento da rede no } \\
\text { mercado }\end{array}$ \\
\hline
\end{tabular}

Fonte: Desenvolvido pelos autores

\section{IMPLICAÇÕES DA PESQUISA}

Após a análise dos dados coletados, esta seção apresenta uma síntese dos resultados, além de discutir e explicar os elementos que fizeram parte da fusão das redes Vida, Farmavale e Vida \& Saúde.

Este estudo identificou a existência de quatro grandes categorias que motivaram a fusão entre as redes: necessidades de maior poder de mercado, geração de soluções coletivas, redução de custos e riscos e busca pela maximização dos lucros. Embora com algumas variações de nomenclatura, essas motivações já foram identificadas por outros autores que analisaram a cooperação interorganizacional (Wegner \& Padula, 2011; Balestrin \& Verschoore, 2008). Ao buscar maior poder de mercado e maximizar lucros, as redes objetivam reduzir a sua dependência em relação ao ambiente externo, em especial seus fornecedores, conforme previsto pela Teoria da Dependência de Recursos (Pfeffer \& Salancik, 2003). Além disso, o relacionamento entre um grupo maior de empresas, originalmente vinculadas a três redes distintas, proporciona maior geração de soluções coletivas e reduz riscos. Essas são motivações para a cooperação postuladas pela Visão Relacional (Dyer \& Singh, 1998), à medida que são diretamente geradas pelas relações estabelecidas entre as empresas.

Quanto ao processo, a fusão que resultou na rede Vida Farmácias mantém o conceito de cooperação em sua essência: um conjunto de organizações [neste caso, redes] que articulam suas atividades para alcançar objetivos coletivos (Balestrin \& Verschoore, 2008; Wegner \& Zonatto, 2013). O caso confirma que "a cooperação não se sustenta com relações díspares: ou todos ganham juntos, ou todos perdem juntos" (Balestrin \& Verschoore, 2008, p. 40). No caso da fusão pesquisada, todos esses elementos foram considerados: as quatro redes (incluindo a Total Farma, que desistiu da fusão ao longo do processo) tinham estruturas parecidas e o mesmo objetivo inicial de agregar mais lojas para aumentar o volume de compras. A sequência de etapas utilizadas pelas redes para realizar o processo de fusão mostrou-se distinta das estratégias tradicionais de cooperação interorganizacional (Balestrin \& Verschoore, 2008; Latorre, 2013). Não houve uma estratégia previamente traçada para efetivar a cooperação e a única certeza dos envolvidos era a necessidade de aumentar o número de lojas, agregando maior volume de compras. A partir daí, os entrevistados destacam que o processo foi acontecendo naturalmente. É o que Mintzberg (2006) chama de estratégia emergente, em que as ações são realizadas sem que haja um planejamento prévio de todas as etapas e ações a serem desenvolvidas.

Apesar de destacarem a inexistência de planejamento prévio, percebe-se que intrinsecamente os passos descritos pela literatura ocorreram. Latorre (2013, p. 55), por exemplo, destaca que "a pesquisa, a seleção e a negociação com empresas candidatas constitui um dos pilares fundamentais", sendo que todos esses elementos foram observados na formação da rede Vida Farmácias. No entanto, uma implicação do caso para a teoria organizacional é que a seleção de parceiros ocorreu a partir de contatos e relações sociais prévias dos envolvidos, e não por meio de uma metodologia clara de análise e seleção.

Ao mesmo tempo em que se conheciam melhor, as empresas participantes das quatro redes elegeram representantes para tratar da fusão. Cada uma delas nomeou quatro nomes, totalizando 16 pessoas responsáveis por toda a negociação. Ferrigolo (2013, p. 34) destaca que o momento da negociação é um "momento ímpar, após um longo período de namoro, com procuras, acenos, discussões e avaliações". Em julho de 2013, após quase um ano de namoro, Vida, Farmavale e Vida \& Saúde oficializaram a criação da nova rede. $\mathrm{O}$ estatuto foi elaborado, contemplando as melhores ideias de cada uma das redes participantes, e 
a nova diretoria foi eleita por aclamação. Como implicação gerencial, o caso analisado revela a importância de manter o equilíbrio de representação das redes envolvidas ao longo do processo de fusão, evitando assimetrias informacionais e de poder que poderiam comprometer o resultado final.

Os benefícios obtidos a partir da fusão das três redes estão alinhados com os pressupostos da Teoria da Dependência de Recursos e a Visão Relacional. Obtenção de poder de mercado e maior legitimidade reduzem a dependência de recursos das empresas envolvidas, como previsto por Pfeffer \& Salancik (2003). A geração de soluções e aprendizagem coletiva, assim como a inovação colaborativa são benefícios da colaboração previstos na perspectiva da Visão Relacional (Dyer e Singh, 1998). De acordo com essa perspectiva, a combinação dos recursos trazidos pelos envolvidos na cooperação gera ganhos relacionais superiores àqueles possíveis pela atuação individual. Esses resultados da cooperação foram evidenciados pelos entrevistados nas possibilidades de competir em igualdade com as grandes empresas do mercado, aumentar seu poder de mercado, potencializar ações de marketing, treinar funcionários e implementar um cartão fidelidade. Uma síntese dos resultados da pesquisa é apresentada na Figura 2.

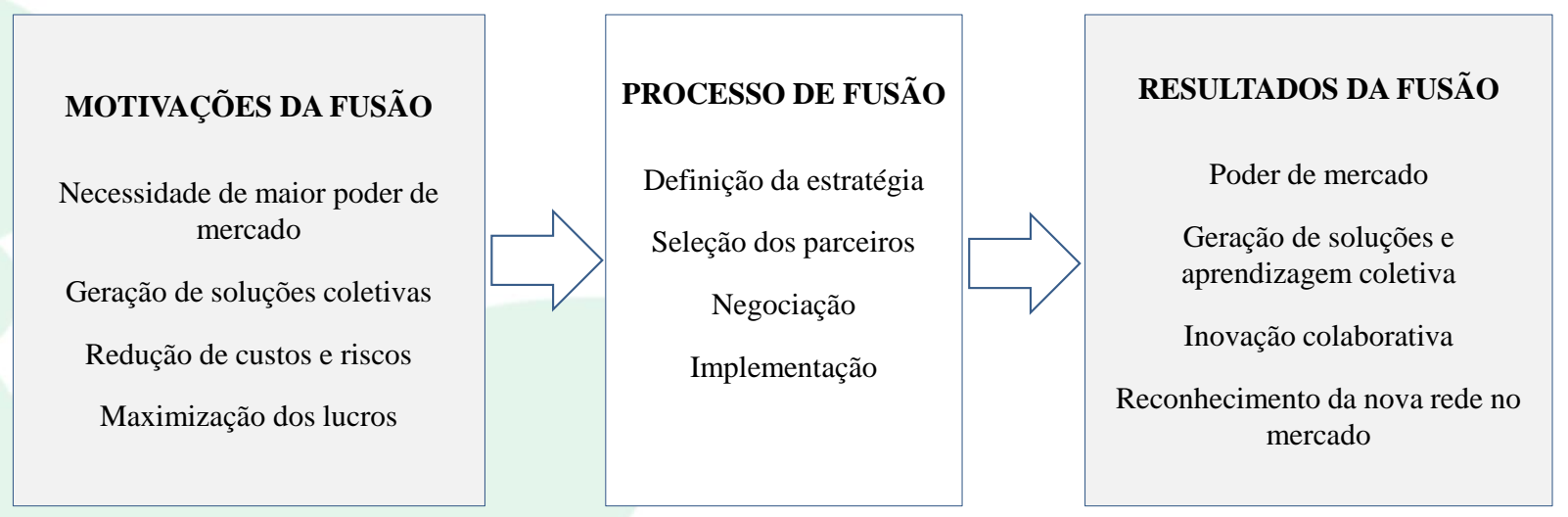

Figura 2 - Síntese dos resultados a pesquisa Fonte: Desenvolvido pelos autores

Como implicação geral do caso analisado, pode-se afirmar que a fusão entre redes é uma estratégia de crescimento possível para redes de cooperação que precisam ampliar seu poder de mercado e gerar novas vantagens competitivas. Gro $\beta$ (2003) classifica a fusão como uma estratégia de crescimento horizontal, permitindo sinergias e complementaridades entre as redes envolvidas. Diferente do crescimento orgânico, por meio da penetração de mercado e atração de novos membros (Groß, 2003), adotado por muitas redes de cooperação, a fusão acelera a obtenção de ganhos à medida que redes já estruturadas unem-se para formar uma estrutura maior (Wegner e Padula, 2011). No entanto, não se deve desconsiderar a complexidade desse processo, uma vez que as redes envolvidas possuem trajetórias, culturas e identidades peculiares que precisam ser acomodadas e ajustadas.

\section{CONSIDERAÇÕES FINAIS}

Este artigo teve como objetivo principal analisar o processo de fusão entre redes empresariais, o qual foi alcançado por meio de um estudo de caso de abordagem qualitativa. A análise de um caso único - a fusão de três redes de empresas, constituindo uma nova rede - permitiu alcançar o objetivo proposto e gerar contribuições à teoria e à prática gerencial. Como principal contribuição, o estudo descreve o processo de fusão adotado pelas redes empresariais, além de apresentar as motivações e os resultados alcançados nesse processo. Embora a estratégia de fusão seja amplamente retratada na literatura organizacional, não foram encontrados estudos que tenham tratado deste tema no contexto de redes empresariais de caráter cooperativo. As características dessas redes, formadas por pequenas empresas e baseadas em um modelo democrático e participativo, tornam mais complexa a implementação de uma estratégia de fusão. Nesse sentido, ao descrever as etapas seguidas no caso estudado, esta pesquisa contribui para a teoria sobre relações interorganizacionais.

Do ponto de vista gerencial, o estudo gera recomendações sobre como as redes podem implementar estratégias de fusão, dando subsídios para outras redes que queiram crescer pela estratégia de fusão. Além disso, esta pesquisa traz a experiência de uma rede do segmento de farmácias, que pode ser aplicado a diversas outras, independente do ramo de atividade. Além de incentivar novas redes a refletirem sobre a estratégia de fusão, os resultados do estudo podem estimular gestores públicos a desenvolver programas de apoio ao fortalecimento e à consolidação das redes. Aproximar redes de um mesmo segmento e fomentar a intercooperação e a fusão pode contribuir 
para torná-las mais competitivas e capazes de sobreviver em um mercado altamente competitivo.

A principal limitação deste trabalho consiste na opção por um estudo de caso único, o que impossibilita extrapolar os resultados do processo de fusão para além do caso analisado. No entanto, ao mesmo tempo em que se reconhece esta limitação, cabe destacar o fato de que a fusão entre redes empresariais é um fenômeno recente e ainda não explorado, o que contribui para justificar a relevância do estudo. Trabalhos futuros podem ampliar essa compreensão por meio de novos estudos de caso e pela análise de outras estratégias de crescimento adotadas por redes empresariais, como, por exemplo, a intercooperação, onde redes se aproximam no intuito de conseguir vantagens competitivas sem formalizar a parceria e sem que as redes individuais percam sua identidade e autonomia.

\section{REFERÊNCIAS}

Ahuja, G. (2000). Collaboration networks, structural holes, and innovation: A longitudinal study. Administrative Science Quarterly, 45(3): 425-455.

Balestrin, A. \& Arbage, A. P. (2007). A perspectiva dos custos de transação na formação de redes de cooperação. RAE-eletrônica, 6(1): 1-25.

Balestrin, A. \&Vargas, L. (2004). A Dimensão estratégica das redes horizontais de PMEs: teorizações e evidências. Revista de Administração Contemporânea, 45: 203-227.

Balestrin, A. \& Verschoore, J. (2008). Redes de cooperação empresarial: estratégias de gestão na nova economia. Porto Alegre: Bookman.

Bardin, L. (1977). Análise de Conteúdo. Lisboa, Portugal: LDA.

Barney, J. \& Hesterly, W. (2008). Administração estratégica e vantagem competitiva. São Paulo: Pearson Prentice Hall.

Brass, D., Galaskiewicz, J., Greve, H. \& Tsai, W. (2004). Taking stock of networks and organizations: A multilevel perspective. Academy of Management Journal, 47(6): 795-817.

Burger, A. Avaliação de empresas. In: Roth, A. \& Antonioni, A. (2013). Alianças empresariais: estratégias para aumento da competitividade das empresas do Setor de TI. Campinas: Softex, 69-83.

Camargos, M. \& Barbosa, F. (2003). Fusões, aquisições e takeovers: um levantamento teórico dos motivos, hipóteses testáveis e evidências empíricas. Caderno de Pesquisas em
Administração, 10(2): 17-38.

Castells, M. (1999). A sociedade em rede. São Paulo: Paz e Terra.

Dyer, J. H. \& Singh, H. (1998). The relational view: Cooperative strategy and sources of interorganizational competitive advantage. Academy of management review, 23(4): 660-679.

Ferrigolo, R. (2013). Planejamento estratégico. In: Roth, A. \& Antonioni, A. Alianças empresariais: estratégias para aumento da competitividade das empresas do Setor de TI. Campinas: Softex, 93103.

Frohlich, H. (2003). Mitgliederintegration, Mitgliederkommunikation und Datenvernetzung. In: Wieselhuber (Ed.). Erfolg im Handel: Praxis des Kooperationsmanage-ments. Frankfurt am Main: Deutscher Fachverlag.

Gil, A. (1999). Métodos e técnicas de pesquisa social. São Paulo: Atlas.

Godoi, C., Mello, R. \& Silva, A. (2006). Pesquisa qualitativa em estudos organizacionais: paradigmas, estratégias e métodos. São Paulo: Saraiva.

Gomes-Casseres, B. (1994). Group versus Group: how alliance networks compete. Harvard: Business Review, 62-74.

Gro $\beta$, W. (2003). Strategische Entwicklungsrichtungen für Verbundgruppen des Handels. In: Wieselhuber (Ed.).Erfolg im Handel: Praxis des Kooperationsmanagements. Frankfurt am Main: Deutscher Fachverlag.

Hitt, M., Ireland, D. \& Hoskisson, E. (2002). Administração estratégica. São Paulo: Thomson.

Latorre, M. (2013). Pesquisa, seleção e negociação inicial com empresas candidatas para a aliança empresarial. In: Roth, A. \& Antonioni, A. Alianças empresariais: estratégias para aumento da competitividade das empresas do Setor de TI. Campinas: Softex, 55-67.

Latorre, M. (2013). Plano de integração de empresas. In: Roth, A. \& Antonioni, A. Alianças empresariais: estratégias para aumento da competitividade das empresas do Setor de TI. Campinas: Softex, 105-121.

Lazzarini, G. (2007). Mudar tudo para não mudar nada: análise da dinâmica de redes de proprietários no Brasil como "mundos pequenos". Revista de Administração de Empresas. RAE Eletrônica, 7(3): $1-25$. 
Leon, M. (1998). Uma análise de redes de cooperação das pequenas e médias empresas do setor das telecomunicações. Dissertação (Engenharia de Produção da Escola Politécnica - Mestrado) Universidade de São Paulo: São Paulo.

Mañas, A. \& Pacanhan, M. (2004). Alianças estratégicas e redes associativistas como fonte de vantagem competitiva no varejo de material de construção. Revista Brasileira de Gestão de Negócios. São Paulo, 6(14): 14-33.

Marconi, M. \& Lakatos, E. (2003). Fundamentos da metodologia científica. São Paulo: Atlas.

Mascarenhas, S. (2012). Metodologia científica. São Paulo: Pearson Education Brasil.

Mintzberg, H., Lampel, J., Quinn, J. \& Ghoshal, S. (2006). O processo da estratégia: conceitos, contextos e casos. Porto Alegre: Bookman.

Olave, L. \& Amato, A. (2001). Redes de cooperação produtiva: uma estratégia de competitividade para pequenas e médias empresas. Gestão e Produção, 8(3): 289-303.

Oliveira, M. \& Gonçalves, C. (2011). Estratégia cooperativa em redes organizacionais: um estudo em polo turístico de Minas Gerais. Revista IberoAmericana de Estratégia, 10(2): 34-57.

Oliver, C. (1990). Determinants of interorganizational relationships: Integration and future directions. Academy of Management Review, 15(2): 241-265.

Olson, M. (1999). A lógica da ação coletiva. São Paulo: Edusp.

Pereira, B. \& Pedrozo, E. (2004). O outro lado da cooperação: uma análise dos problemas na gestão das redes interorganizacionais. In: Verschoore, J. Redes de cooperação: uma nova organização de pequenas e médias empresas no Rio Grande do Sul. Porto Alegre: FEE 69-88.

Pfeffer, J \& Salancik, G. R. (2003). The external control of organizations: A resource dependence perspective. Stanford University Press.

Porter, M. (1996). Estratégia competitiva: técnicas para análise da indústria e da concorrência. Rio de Janeiro: Campus.

Provan, K. \& Kenis, P. (2007). Modes of network governance: Structure, management and effectiveness. Journal of Public Administration Research and Theory, 18(2): 229-252.

Richardson, R. J. (1999). Pesquisa social: métodos e técnicas. São Paulo: Atlas, $3^{\mathrm{a}}$ edição.
Santos, D. D. dos \& Teixeira, R. M. (2005). Redes interorganizacionais de PMEs: fatores de cooperação e aprendizado. In: EGEPE - Encontro de Estudos Sobre Empreendedorismo e Gestão de Pequenas Empresas. Anais. Curitiba: 1289-1300.

Sebrae. (2012) Central de negócios: empresas unidas se tornam mais competitivas. Disponível em $<$ http://www.sebrae.com.br/sites/

PortalSebrae/sebraeaz/Central-de-

Neg\%C3\%B3cios:-empresas-unidas-se-tornammais-competitivas>. Acesso em: 27 mar. 2014.

Sebrae. (2012) Mapeamento das centrais e redes de negócios. Disponível em <http://www.sebrae.com.br/sites/PortalSebrae/>. Acesso em: 15 abr. 2014.

Tálamo, J. R. \& Carvalho, M. M. C. (2010). Redes de cooperação com foco em inovação: um estudo exploratório. Gestão da Produção. 17(4): 747-760.

Todeva, E. (2006). Business networks: strategy and structure. London: Toutledge.

Toigo, T. \& Alba, G. R. (2010). Programa Redes de Cooperação do estado do Rio Grande do Sul: Perfil das Redes de Empresas acompanhadas pela Universidade de Caxias do Sul. XIII Semead Seminários em Administração. Anais. São Paulo: Edusp.

Verschoore, J. (2004). Redes de cooperação: uma nova organização de pequenas e médias empresas no Rio Grande do Sul. Porto Alegre: FEE.

Verschoore, J. \& Balestrin, A. (2008). Ganhos competitivos das empresas em redes de cooperação. Revista de Administração da Universidade de São Paulo Eletrônica (RAUSP-e), 1(1): 1-21.

Vida Farmácias. (2013-2014) Desenvolvido pela Vida Farmácias. Apresenta informações gerais sobre a instituição. Disponível em <http://www.vidafarmácias.com.br/site/>. Acessado em 18 abr, 2014.

Wegner, D., Alievi, R. M. \& Begnis, H. S. M. (2015). The life cycle of small-firm networks: An evaluation of Brazilian business networks. BAR. Brazilian Administration Review, 12(1): 39-62.

Wegner, D., \& Padula, A. D. (2010). Tendências da cooperação em redes horizontais de empresas: o exemplo das redes varejistas na Alemanha. Revista de Administração da Universidade de São Paulo, 45(3).

Wegner, D. \& Padula, A. (2011). Estratégias de crescimento e a governança de redes horizontais de 
empresas: o caso da maior rede cooperativa de varejo de alimentos na Alemanha. Revista de Ciências da Administração, 13(30): 220-248.

Wegner, D. \& Padula, A. (2010). Tendência da cooperação em redes horizontais de empresas: $\mathrm{O}$ exemplo das redes varejistas na Alemanha. Revista de Administração da USP, 45(3): 221-237.

Wegner, D. \& Zonatto, P. (2013). Redes e relações interorganizacionais: modelos organizacionais baseados na colaboração. In: Faccin, K., Avila, R. \& Guimarães, J. Relações de trabalho: desafios da educação. Caxias do Sul, FSG: 262-287.

Wegner, D., Wittmann, M. \& Dotto, D. (2006). Redes de empresas no Rio Grande do Sul: uma análise de resultados competitivos e fatores de desenvolvimento. Revista Eletrônica de Gestão Organizacional, 4(1): 74-90.

Wellenbeck, M. (2001). Zentralregulierung der NordWest-Ring- Gruppe. In: Zentes, J. \& Swoboda, B. (Ed.). Perspektiven der Zentralregulierung. Frankfurt am Main: Dt. Fachverlag.
Williamson, O. E. (1975). Markets and hierarchies: Analysis and antitrust implications. New York, NY: Free Press.

Xavier, J., Chagas, R., Santos, S., Romero, C. \& Carneiro, M. (2010). Proposta de modelo para avaliação da contribuição de centrais de negócio para a empresa participante: o caso da central de negócio "rede âncora de autopeças". Revista de Negócios, 15(4): 113-136.

Yin, R. (2005). Estudo de caso: planejamento e métodos. Porto Alegre: Bookman.

Zancan, C., Santos, P., Costa, A. \& Cruz, N. (2013). Condicionantes de consolidação de redes de cooperação interorganizacional: um estudo de caso sobre o Rio Grande do Sul. Revista Administração Pública, 47(3): 647-669.

Williamson, O. E. (2005). The economics of governance. The American Economic Review, 95(2): 1-18 